\title{
Fibroblast growth factor-21 (FGF21) administration to early-lactating dairy cows. I. Effects on signaling and indices of insulin action
}

\author{
C. S. Krumm, ${ }^{1 *}$ S. L. Giesy, ${ }^{1 *}$ L. S. Caixeta, ${ }^{1} \odot$ J. W. Perfield 2 nd,${ }^{2}$ H. Sauerwein, ${ }^{3} \odot$ B. L. Moore, ${ }^{1}$ \\ and Y. R. Boisclair ${ }^{1}+$ (D) \\ ${ }^{1}$ Department of Animal Science, Cornell University, Ithaca, NY 14853 \\ ${ }^{2}$ Lilly Research Laboratories, Eli Lilly and Company, Indianapolis, IN 46285 \\ ${ }^{3}$ Institute of Animal Science, Physiology, and Hygiene Unit, University of Bonn, 53115 Bonn, Germany
}

\section{ABSTRACT}

Modern dairy cows rely on hormonally driven mechanisms to coordinate the metabolic adaptations needed to meet the energy and nutrient deficits of early lactation. In the case of glucose, dairy cows cope with its scarcity during early lactation via reduced plasma concentrations of insulin and the insulin sensitizing hormone adiponectin and increased insulin resistance. Reduced insulin action promotes diversion of available glucose to the mammary gland but increases susceptibility to diseases if excessive. In earlier work, we reported that the insulin sensitizing hormone fibroblast growth factor-21 (FGF21) is increased in periparturient dairy cows and identified liver and adipose tissue as possible targets. These observations raised the possibility that FGF21 acts directly on these tissues to limit the insulin resistance of early lactation. To test this hypothesis, dairy cows were randomly assigned on d $12.6 \pm 2.2( \pm$ standard error) of lactation to receive either excipient $(\mathrm{n}=6)$ or recombinant human FGF21 $(\mathrm{n}=7)$, first as an FGF21 bolus of $3 \mathrm{mg} / \mathrm{kg}$ of body weight, followed $2 \mathrm{~d}$ later by a constant i.v. infusion of FGF21 at the rate of $6.3 \mathrm{mg} / \mathrm{kg}$ of metabolic body weight for 9 consecutive days. Biopsies of liver and adipose tissue were collected during the bolus phase of the experiment and used to analyze FGF21 signaling by Western blotting and expression of its receptor components by quantitative PCR. Bolus FGF21 administration caused a 4-fold increase in p44/42 MAPK (ERK1/2) activation in adipose tissue but had no effect on AKT and signal transducer and activator of transcription-3

Received March 27, 2019

Accepted August 5, 2019.

*These authors contributed equally to this work.

†Corresponding author: yrb1@cornell.edu
(STAT3) signaling. The liver expressed negligible levels of the preferred FGF21 receptor FGFR1c and failed to mount any FGF21 signaling response. The FGF21 administered as a bolus had no effect on plasma glucose or insulin and did not stimulate an acute release of adiponectin from adipose tissue. Similarly, FGF21 infusion had no effect on plasma levels of glucose or insulin measured over the 9-d infusion or on glucose disposal during an i.v. glucose tolerance test performed on d 8 of infusion. Finally, the chronic FGF21 infusion had no effect on indices of adiponectin production, including plasma adiponectin and adipose tissue mRNA abundance of adiponectin and the endoplasmic reticulum chaperones ERO1A and DSBA-L involved in the assembly of adiponectin into multimeric complexes. These data show that human FGF21 does not act as an insulin sensitizer during the energy and glucose deficit of early lactation but do not rule out such a role in other physiological states.

Key words: adiponectin, adipose tissue, glucose, insulin resistance, liver

\section{INTRODUCTION}

The onset of lactation in modern dairy cows is associated with substantial deficits in energy and dietary-derived nutrients. Bell (1995) illustrated the extent of this metabolic challenge by comparing the glucose economy between late pregnancy and d 4 of lactation. The switch from the gravid uterus to the mammary gland as the major glucose utilizing organ led to an increase in glucose need from $\sim 666$ to $1,775 \mathrm{~g} / \mathrm{d}$ when expressed in absolute terms or from 45 to $85 \%$ when expressed as a fraction of the total maternal glucose supply (Bell, 1995). This sudden increase is compounded further by the absence of an adequate matching increase in voluntary feed intake after parturition, leading to a sustained deficit in dietary-derived glucose precursors (Bell, 1995; Drackley et al., 2001). Dairy cows cope with this chal- 
lenge by mounting several hormonally driven adaptations including reductions in the plasma concentrations of insulin and the insulin sensitizing hormone adiponectin and rising insulin resistance in selected peripheral tissues (Block et al., 2001; Giesy et al., 2012; De Koster and Opsomer, 2013). These adaptations divert the available glucose supply to the mammary gland where uptake is independent of insulin (Bell and Bauman, 1997), but if excessive, they also have the unintended consequence of increasing susceptibility to diseases such as ketosis (Drackley et al., 2001; Boisclair et al., 2006; De Koster and Opsomer, 2013).

The last few years have seen the discovery of a novel class of hormones acting predominantly as insulin sensitizers (Markan and Potthoff, 2016; Stern et al., 2016). Among those, fibroblast growth factor- 21 (FGF21) has received considerable attention as a possible therapy for insulin resistance (Fisher and Maratos-Flier, 2016; Markan and Potthoff, 2016). The FGF21 belongs to the FGF superfamily, but unlike most other FGF, FGF21 lacks the heparin binding domain. Absence of this domain has 2 major consequences: first, FGF21 cannot be retained at the site of production by proteoglycans and therefore enters the circulation; and second, formation of high affinity binding with fibroblast growth factor receptor (FGFR) isoforms requires the presence of the co-receptor $\beta$-Klotho (Ogawa et al., 2007; Kharitonenkov et al., 2008). Remarkably, FGF21 therapy normalizes circulating concentrations of glucose and insulin and reverses insulin resistance in rodents and primates suffering from obesity or type 2 diabetes or both (Kharitonenkov et al., 2007; Xu et al., 2009a). These beneficial effects are associated with increased plasma concentration of the insulin-sensitizing hormone adiponectin and are impaired in adiponectin knockout mice (Holland et al., 2013; Lin et al., 2013). We previously reported a sudden increase in plasma FGF21 around parturition followed by chronically elevated levels over the next few weeks and identified liver and adipose tissue as possible FGF21 target tissues on the basis of robust expression of the co-receptor $\beta$-Klotho (Schoenberg et al., 2011).

These observations led us to hypothesize that increased FGF21 in early lactation serves as a feedback mechanism to counter peripheral insulin resistance. Accordingly, we administered exogenous FGF21 to early-lactating dairy cows to determine first, whether liver and adipose tissue are direct FGF21 target tissues and second, whether FGF21 exerts insulin sensitizing actions. Our results identify adipose tissue as the predominant peripheral FGF21 responsive tissue but do not support an insulin-sensitizing role for FGF21 during the energy deficit of early lactation.

\section{MATERIALS AND METHODS}

\section{Animals and Design}

All procedures were conducted with the approval of the Cornell University Institutional Care and Use Committee. Fourteen Holstein dairy cows were moved to a controlled environment $\left(20^{\circ} \mathrm{C}\right.$, light on $0500-2100$ h) on d $9.7 \pm 2.2$ of lactation and fitted with bilateral intrajugular vein catheters. One cow became ill before initiation of treatment and therefore was removed from the study. The remaining 13 cows were of uniform parity $(2.3 \pm 0.2 ; \pm \mathrm{SE})$ and body condition $(3.5 \pm$ 0.2 ). They were housed in individual stalls and offered nonlimiting amounts of an early lactation TMR (1.63 Mcal of $\mathrm{NE}_{\mathrm{L}}$ and $16.3 \%$ of $\mathrm{CP}$ per $\mathrm{kg}$ of $\mathrm{DM}$ ) every 2 $\mathrm{h}$ using in-house automatic feeders. Cows were milked daily at 0700 and $1700 \mathrm{~h}$. Additional details regarding diet composition and animal performance are given in a companion paper (Caixeta et al., 2019).

Cows were randomly allocated to excipient solution (control; $\mathrm{n}=6$ ) or recombinant human FGF21 (FGF21; $\mathrm{n}=7$ ) and studied in 2 consecutive phases. In the first phase, treatments were administered as a single intrajugular bolus at $0800 \mathrm{~h}$ on d $12.6 \pm 2.2$ of lactation. The FGF21 dose was $3 \mathrm{mg} / \mathrm{kg}$ of BW and was selected on the basis of positive responses when given as a single injection in the mouse (Xu et al., 2009b). The dose was prepared with the human FGF21 variant LY2405319 with $78 \%$ identity with mature bovine FGF21 and engineered for enhanced in vivo stability and retaining full biological activity (Adams et al., 2013; Kharitonenkov et al., 2013). LY2405319 was produced in Pichia pastoris, purified to homogeneity using reverse phase and anion exchange chromatography, and prepared as a 33 $\mathrm{mg} / \mathrm{mL}$ solution in an excipient solution of $10 \mathrm{mM}$ citrate, $150 \mathrm{~m} M \mathrm{NaCl}$, pH 7.0 (Eli Lilly, Indianapolis, IN; Kharitonenkov et al., 2013). The LY2405319 solution was kept frozen until used as done in previous studies in humans and monkeys (Adams et al., 2013; Gaich et al., 2013). Blood samples were obtained at fixed times relative to bolus administration $(-60,-30,0,1,5,10$, 20, 40, and $60 \mathrm{~min}$ and 1.5, 2, 3, 4, 6, 8, 10, and 12 h), immediately mixed with heparin $(15 \mathrm{IU} / \mathrm{mL})$ and centrifuged at $3,000 \times g$ for $15 \mathrm{~min}$ at $4^{\circ} \mathrm{C}$. Resulting plasma was stored at $-20^{\circ} \mathrm{C}$ until analyzed for metabolites and hormones. Liver and adipose tissue biopsies were obtained at $-15,+15$, and +30 min relative to bolus administration. Biopsies involved surgical preparation and local anesthesia, followed by percutaneous puncture with a biopsy trocar for liver and dissection of the tailhead depot for white adipose tissue (WAT) as previously described (Giesy et al., 2012; Caixeta et al., 
2017). For liver, all biopsies were taken through a single skin incision; for adipose tissue, repeated biopsies were obtained $\sim 1$ inch $(2.54 \mathrm{~cm})$ apart through a single incision of one of the tailhead fat depots. Biopsied tissues were snap-frozen in liquid nitrogen and stored at $-80^{\circ} \mathrm{C}$ until further analysis.

The second phase was initiated $2 \mathrm{~d}$ later at $0800 \mathrm{~h}$ and involved continuous intrajugular infusion of either excipient or FGF21 solution for 9 consecutive days. The daily FGF21 dose was $6.3 \mathrm{mg} / \mathrm{kg}$ of metabolic BW and was selected on the basis of positive responses when administered chronically to rhesus monkeys (Adams et al., 2013). The LY2405319 was prepared in excipient solution as described above, and both excipient and LY2405319 solutions were infused at the fixed rate of 5 $\mathrm{mL} / \mathrm{h}$ using a syringe pump. Blood samples were collected at $0,1,3$, and $8 \mathrm{~h}$ relative to the start of the infusion and at $0800 \mathrm{~h}$ on subsequent days. An i.v. glucose tolerance test (GTT) was performed at $1400 \mathrm{~h}$ on d 8 of infusion. The glucose dose was $0.25 \mathrm{~g}$ of glucose per $\mathrm{kg}$ of BW administered as a dextrose solution (50\% wt/ vol, VetOne, Boise, ID). Blood samples were collected at $-60,-30,-15,-5,5,10,20,30,60,90$, and $120 \mathrm{~min}$ relative to administration of the glucose bolus. Finally, WAT biopsies were taken at the end of infusion on $\mathrm{d}$ 9 from the contralateral tailhead fat depot. Collected blood samples and tissue biopsies were processed and stored as described above.

\section{Analysis of Metabolites and Hormones}

Plasma glucose was analyzed by spectrophotometric methods based on the enzyme glucose oxidase (Caixeta et al., 2017). The plasma concentration of insulin was determined using double-antibody assays (porcine insulin RIA, Millipore; Burlington, MA; Caixeta et al., 2017). For the GTT, plasma glucose and insulin response areas were calculated between 0 and $90 \mathrm{~min}$ and were corrected for baseline concentrations (mean of concentrations at $-60,-30,-15$, and $-5 \mathrm{~min}$ for glucose and -60 and $-15 \mathrm{~min}$ for insulin; Sechen et al., 1989; Ehrhardt et al., 2001). Plasma adiponectin was assayed with a bovine adiponectin ELISA (Mielenz et al., 2013) as modified by (Krumm et al., 2017). Inter- and intraassay coefficients of variation were respectively $<10 \%$ and $<6 \%$ for the glucose assay and $<8 \%$ and $<8 \%$ for all hormone assays.

\section{Western Immunoblotting}

Liver and WAT were homogenized in $1 \mathrm{~mL}$ of lysis buffer $(10 \mathrm{~m} M$ Tris, $\mathrm{pH} 7.6,10 \mathrm{~mL} / \mathrm{L}$ of Triton
$\mathrm{X}-100,1 \mathrm{~m} M$ EGTA, $150 \mathrm{~m} M \mathrm{NaCl}, 1 \mathrm{~m} M \mathrm{Na}_{3} \mathrm{VO}_{4}, 1$ $\mathrm{m} M$ Na pyrophosphate, $10 \mathrm{~m} M \mathrm{NaF}, 1 \mathrm{~m} M$ EDTA, 1 $\mathrm{m} M$ phenylmethylsulfonyl fluoride, $10 \mathrm{mg} / \mathrm{L}$ of aprotinin, and $10 \mathrm{mg} / \mathrm{L}$ of leupeptin). Homogenates were clarified by centrifugation $(10,000 \times g$ for $20 \mathrm{~min}$ at $4^{\circ} \mathrm{C}$ ). Protein concentrations of cellular extracts were determined using a bicinchoninic acid protein assay kit (Thermo Fisher, Waltham, MA). Fixed amounts (50 $\mu \mathrm{g})$ of protein extract were separated on 10 to $13 \%$ polyacrylamide gels and transferred onto nitrocellulose membranes (Protran, Schleicher, and Schuell Bioscience, Dassel, Germany). Membranes were immersed in blocking solution (50 mM Tris, $\mathrm{pH} 7.4,200 \mathrm{mM} \mathrm{NaCl}$, $1 \mathrm{~mL} / \mathrm{L}$ of Tween $20,50 \mathrm{~g} / \mathrm{L}$ of nonfat dried skim milk). For adiponectin detection, membranes were immunodecorated overnight at $4^{\circ} \mathrm{C}$ in blocking solution containing a 1:20,000 dilution of a primary antibody against human adiponectin (a gift from T. Funahashi, Osaka University, Osaka, Japan) validated in cattle (Krumm et al., 2018). For signaling proteins, membranes were incubated with 1:1,000 dilution of primary antibodies obtained from Cell Signaling (Danvers, MA) against p44/42 MAPK (ERK1/2), threonine 202/tyrosine 204 phosphorylated ERK1/2 (pERK1/2), signal transducer and activator of transcription-3 (STAT3), tyrosine 705 phosphorylated Stat3 (pSTAT3), and $\beta$-actin. Each antibody is reported by the supplier to have specificity for their target bovine protein as confirmed in our previous work (Thorn et al., 2006). Signals were developed with a 1:20,000 dilution of IRDye 800 anti-rabbit or anti-mouse secondary antibody (LI-COR Biotechnology, Lincoln, NE) followed by visualization and quantification with the LI-COR Odyssey infrared imaging system using the 800-nm channel.

\section{RNA Extraction and Analysis of Gene Expression}

Liver and WAT samples were lysed with Qiazol (Qiagen, Valencia, CA) followed by total RNA purification using RNeasy Mini columns and on-column RNase-free DNase treatment (Qiagen). Quality of RNA was determined using the RNA Nano Lab Chip kit and bioanalyzer (Agilent, Palo Alto, CA) with all samples having RNA integrity number $\geq 7.5$. Reverse transcription reactions were performed with $1 \mu \mathrm{g}$ of total RNA in a total 20 $\mu \mathrm{L}$ volume with the high-capacity cDNA reverse transcription kit and RNase inhibitor (Applied Biosystems, Foster City, CA). Gene expression was analyzed by quantitative real-time PCR using Power SYBR Green Mix (Applied Biosystems). Real-time PCR assays were performed in duplicate with a total $25 \mu \mathrm{L}$ reaction volume containing $500 \mathrm{n} M$ concentration of each primer 
and reverse transcribed mRNA (25 ng except $2.5 \mathrm{ng}$ for the internal standard gene 18S). The sequences of all primers used are given in Supplemental Table S1 (https://doi.org/10.3168/jds.2019-16695). Primer pairs were designed using Primer-BLAST software (http:/ /www.ncbi.nlm.nih.gov/tools/primer-blast/). For all genes, each member of the primer pair was located in adjoining exons and shown by blast analysis to anneal exclusively to the target sequence. For all primer pairs, amplification was $>95 \%$ efficient and yielded a single product verified by melting curve analysis. Data were analyzed using a relative standard curve based on a serial 2-fold dilution of pooled cDNA prepared from WAT samples except when quantifying the relative abundance of the various FGFR isoforms. In this case, the efficiency-corrected change in cycle threshold value method was used as previously described (Fon Tacer et al., 2010; Schoenberg et al., 2011). An arbitrary expression level was obtained by normalizing the efficiencycorrected value for each FGFR. For both methods, data were normalized to the geometric mean of invariant genes. Invariant genes were $\beta$-actin and $G A P D H$ for genes measured exclusively in adipose tissue and $18 \mathrm{~S}$ and $B 2 M$ when comparing expression between liver and adipose tissue.

\section{Statistical Analysis}

Data collected at a single time point were analyzed by a mixed model using the fit model procedure of JMP Pro 11.0 statistical software (SAS Institute Inc., Cary, NC). Specifically, FGFR expression in liver was analyzed by a model accounting for the various isoforms (FGFR1c, FGFR2c, and FGFR3c) as fixed effects and cow as the random effect. Expression of $F G F R$ isoforms was compared by pairwise comparisons with Tukey adjustment. Tissue expression of FGFR and $\beta$-Klotho were compared with a model accounting for tissue (liver vs. adipose tissue) as fixed effect and cow as the random effect. Data collected over time were analyzed by repeated measures using the MIXED procedure of SAS version 9.3 (SAS Institute Inc.). The model accounted for treatment (control vs. FGF21) and Time as fixed effects and cow as the random effect. Cow was subjected to 6 covariance structures (first-order autoregressive, heterogeneous first-order autoregressive, compound symmetry, heterogeneous compound symmetry, firstorder antedependence, and Toeplitz). The structure yielding the smallest Akaike's information criterion was selected. A covariate corresponding to data collected immediately before bolus was included in this model. Statistical significance and tendency were set at $P<$ 0.05 and $P<0.10$, respectively.

\section{RESULTS}

\section{Biological Activity of Human FGF21}

Previous work has identified ERK1/2 activation as the principal FGF21 signaling event and STAT3 and serine/threonine kinase (AKT) activation as sporadic events (Fisher and Maratos-Flier, 2016). Accordingly, we obtained biopsies of adipose tissue immediately before and after bolus administration and measured ERK1/2 signaling by Western immunoblotting. The ERK1/2 signaling, assessed as the abundance of pERK1/2, was detected within 15 min of the FGF21 bolus and remained elevated after $30 \mathrm{~min}$ (Figure 1A). This FGF21 effect translated into a 4-fold increase in ERK1/2 activation, calculated as the ratio of pERK1/2 to total ERK1/2 (Figure 1A, FGF21 $\times$ Time, $P=$ 0.048). Abundance of pERK1/2 in the adipose tissue of control cows remained invariant over the same period. In contrast, FGF21 did not alter STAT3 or AKT phosphorylation (Figure 2B and results not shown).

We analyzed the same signaling events in protein extracts prepared from liver biopsies taken at identical times. This work did not reveal any effect of FGF21 on ERK1/2, STAT3, or AKT signaling (Figure 2C and results not shown). These data show that human FGF21 is biologically active in the early-lactating dairy cow and identify adipose tissue as a major target tissue.

To determine the basis for lack of FGF21 response in liver, we compared expression of $\beta$-Klotho and $F G$ $F R 1 c$ between liver and adipose tissue immediately before bolus treatment. Relative to adipose tissue, liver expressed twice as much of the co-receptor $\beta$-Klotho but only negligible levels of FGFR1c (Figure 2A, $P$ $<0.001)$. Liver had 10-fold higher expression of $F G$ $F R 2 c$ than either FGFR1c or FGFR3c (Figure 2B, $P$ $<0.001$ ), but nevertheless, the combined expression of all these receptor isoforms in liver was still only $37 \%$ of FGFR $1 c$ expression in adipose tissue $(P<0.001)$. These data suggest that the lack of FGF21 responsiveness in the liver of early-lactating dairy cows is due to the insufficient expression of FGFR isoforms capable of FGF21 signaling.

\section{Absence of Acute FGF21 Effects on Plasma Glucose, Insulin, and Adiponectin}

In mice, exogenous FGF21 reduces plasma glucose and insulin within minutes of administration. To determine whether FGF21 is capable of similarly rapid effects in early-lactating dairy cows, glucose and insulin were analyzed in samples collected after the excipient or FGF21 bolus (Figure 3A). The plasma concentrations 
of glucose varied little over the 12-h sampling period with FGF21 treatment having no effect. The plasma concentrations of insulin varied over time (Time, $P=$ 0.001), but again FGF21 treatment had no effect.

A second near immediate effect of FGF21 administration in mice is increased adiponectin secretion. Accordingly, we asked whether elevated FGF21 caused depletion of adiponectin in adipose tissue by performing Western immunoblot analysis on extracts prepared from adipose tissue biopsies taken immediately before and after the bolus. Adiponectin was detected as a single 30 $\mathrm{kDa}$ signal, but its abundance remained unaltered following FGF21 administration (Figure 3B). To extend this result to later times, the plasma concentration of adiponectin was measured by ELISA following bolus administration. The plasma adiponectin concentration averaged 30 and $33 \mu \mathrm{g} / \mathrm{mL}$ for the control and FGF21 groups, but the FGF21 bolus did not significantly increase plasma adiponectin at any time over the 12-h sampling window (Figure 3C). These data indicate that
FGF21 is devoid of acute effects on plasma glucose, insulin, and adiponectin in early-lactating dairy cows.

\section{Absence of Chronic FGF21 Effects on Plasma Glucose, Insulin, and Adiponectin}

Finally, we asked whether FGF21 effects on plasma glucose, insulin, and adiponectin required chronic administration. Two days following bolus administration, treatments were resumed via constant i.v. infusion for 9 consecutive days. The plasma FGF21 concentration over the 9-d infusion period averaged $5.1 \pm 1.5$ and $597 \pm 27.3 \mathrm{ng} / \mathrm{mL}$ for the control and FGF21 groups, respectively (Caixeta et al., 2019).

The profiles of plasma glucose and insulin over the 9-d infusion period are shown in Figure 4A. Plasma glucose remained unchanged, whereas plasma insulin increased over time (Time, $P<0.001$ ); more importantly, FGF21 treatment had no effect on either profile. A GTT was performed on d 8 of infusion to assess

\section{A Adipose tissue}

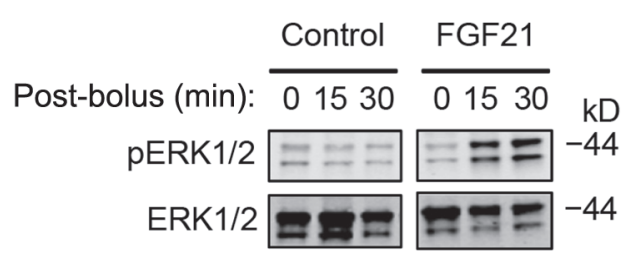

B Adipose tissue

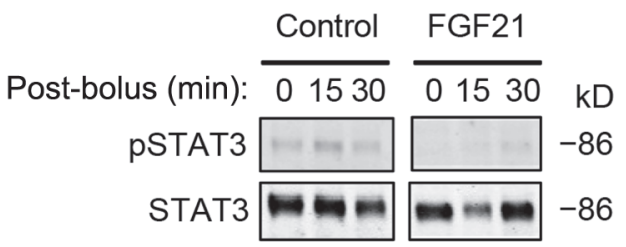

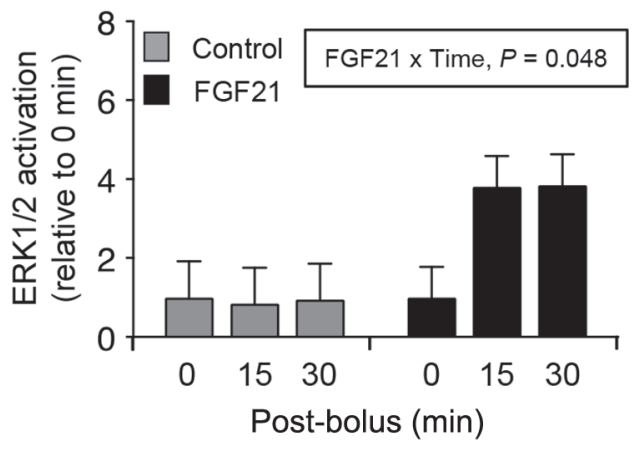

C Liver

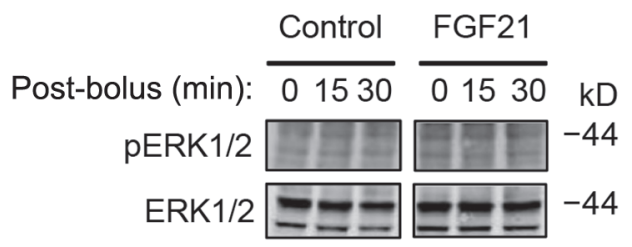

Figure 1. Fibroblast growth factor-21 (FGF21) signaling in white adipose tissue and liver of early-lactating dairy cows. Dairy cows received an i.v. bolus of excipient (control) or human FGF21 (3 mg/kg of BW) on d $12.6 \pm 2.2$ of lactation. Biopsies of adipose tissue and liver were obtained immediately before i.v. bolus at time 0 and then 15 and 30 min later. Total cellular extracts were prepared and analyzed by Western immunoblotting. (A) Left: threonine 202/tyrosine 204 phosphorylated (pERK1/2) and total p44/42 mitogen-activated protein kinase (ERK1/2) abundance in adipose tissue extracts from a representative control and FGF21-treated cow. Right: ERK1/2 activation (ratio of phosphorylated to total ERK1/2) was calculated and expressed relative to time 0, with each bar representing the LSM \pm SE of 6 to 7 cows per treatment. The significant effect of the interaction between FGF21 treatment and time (FGF21 × Time) is reported. (B) Tyrosine 705 phosphorylated Stat3 (pSTAT3) and total signal transducer and activator of transcription-3 (STAT3) abundance in adipose tissue extracts from a representative control and FGF21-treated cow. (C) Threonine 202/tyrosine 204 phosphorylated (pERK1/2) and total ERK1/2 abundance in liver extracts from a representative control and FGF21-treated cow. 
glucose disposal and insulin secretion (Figure 4B). The FGF21 treatment had no effect on the plasma profiles and response areas of glucose and insulin.

We asked whether chronic FGF21 increased adiponectin content by comparing adiponectin abundance in adipose tissue at the start and end of infusion. Adiponectin abundance, assessed by Western immunoblot analysis, did not change significantly for either treatment between d 0 and 9 of the infusion period (Figure 5A). Similarly, the plasma concentration of adiponectin increased over the infusion period but did not differ between treatments (Figure 5B, Time, $P<0.001$ ).

In rodents, the increased plasma adiponectin during chronic FGF21 treatment is accounted for by the positive effects on mRNA abundance of adiponectin and endoplasmic reticulum chaperones contributing to the assembly of adiponectin into multimers. However, chronic FGF21 infusion had no effect on adipose tissue mRNA abundance of either adiponectin or the chaperones endoplasmic reticulum oxidoreductase $1 \alpha$ (ERO1A) and disulfide bond oxidoreductase A-like protein (DSBA-L; Figure 5C). The overall lack of effect of FGF21 on plasma variables reflective of insulin action and on the insulin-potentiating hormone adiponectin

A

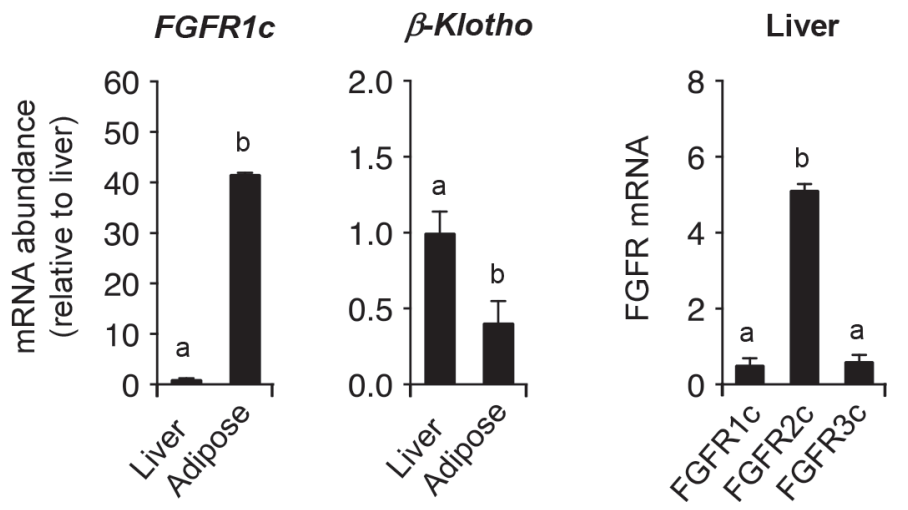

Figure 2. Expression of fibroblast growth factor-21 (FGF21) signaling components in white adipose tissue and liver of early-lactating dairy cows. Evaluation of signaling component mRNA expression was performed in a randomly selected subset of cows. Biopsies of liver and adipose tissue were obtained immediately before i.v. bolus administration on d $12.6 \pm 2.2$ of lactation. The subsequent treatment allocation of these cows was 2 to the excipient group (control) and 4 to the human FGF21 group. (A) Total RNA isolated from liver and adipose tissue was analyzed for the mRNA abundance of FGFR1c and $\beta$-Klotho. Expression is given relative to the liver. Each bar represents the LSM $\pm \mathrm{SE}$ of mRNA abundance for the indicated gene $(\mathrm{n}=6$ cows). Bars with different letters are significantly different at $P<0.001$. (B) Total RNA isolated from liver was analyzed for the mRNA abundance of the FGF receptor (FGFR) isoforms FGFR1c, FGFR2c, and FGFR3c. Each bar represents the LSM $\pm \mathrm{SE}$ of mRNA abundance for the indicated gene $(\mathrm{n}=6$ cows $)$. Bars with different letters are significantly different at $P<0.001$. suggest that human FGF21 does not act as an insulin sensitizer in the early-lactating dairy cow.

\section{DISCUSSION}

Dairy cows meet the nutritional deficits of early lactation by triggering a collection of metabolic adaptations, one of which is reduced insulin action. Reduced insulin action in early lactation results from the combination of hypoinsulinemia and insulin resistance in target tissues (Bell, 1995; Boisclair et al., 2006; De Koster and Opsomer, 2013). Reduced insulin action favors partitioning of glucose to the mammary gland where glucose uptake is insulin independent and facilitates the mobilization of free fatty acids from WAT and AA from skeletal muscle (Bell and Bauman, 1997; Boisclair et al., 2006). Reduced insulin action, however, is excessive in many animals and is associated with diseases such as fatty liver and ketosis, prompting the search for therapies moderating insulin resistance (Drackley et al., 2001; De Koster and Opsomer, 2013). Interestingly, we previously showed a sudden increase in the plasma concentration of the hepatokine FGF21 in periparturient dairy cows (Schoenberg et al., 2011). Exogenous FGF21 administration improves insulin action in rodents and nonhuman primates suffering from type 2 diabetes or obesity or both (Kharitonenkov et al., 2007; Xu et al., 2009b), but whether such actions occur in the energy-deficient early-lactating dairy cow is unknown.

As a first step to address this question, we administered an i.v. bolus of the human FGF21 variant LY2405319 to obtain evidence that it could activate the canonical FGF21 signaling pathway ERK1/2 in cattle. Factors considered in evaluating signaling included FGF21 dose and target tissues. First, we selected the dose of $3 \mathrm{mg} / \mathrm{kg}$ of BW on the basis of robust signaling responses in the mouse with doses ranging from 1 to 10 $\mathrm{mg} / \mathrm{kg}$ of BW (Xu et al., 2009b; Véniant et al., 2012; Lin et al., 2013). Second, FGF21 activates FGFR signaling only in the presence of the co-receptor $\beta$-Klotho, and liver and adipose tissue were the only 2 peripheral tissues expressing meaningful levels of $\beta$-Klotho in our previous work (Schoenberg et al., 2011). Accordingly, we limited our assessment of FGF21 signaling to liver and adipose tissue.

The FGF21 increased ERK1/2 activation in WAT by 4-fold at both $15 \mathrm{~min}$ and $30 \mathrm{~min}$ after i.v. bolus. This agrees with the ability of FGF21 to activate ERK1/2 in adipocyte cell models and adipose tissue of rodent and human origin (Kharitonenkov et al., 2005; Kurosu et al., 2007; Xu et al., 2009b). On the other hand, we could not detect AKT or STAT3 activation in response to FGF21. These signaling events have been seen within 15 min of addition to 3T3-L1 adipocytes and insulin 
A Plasma

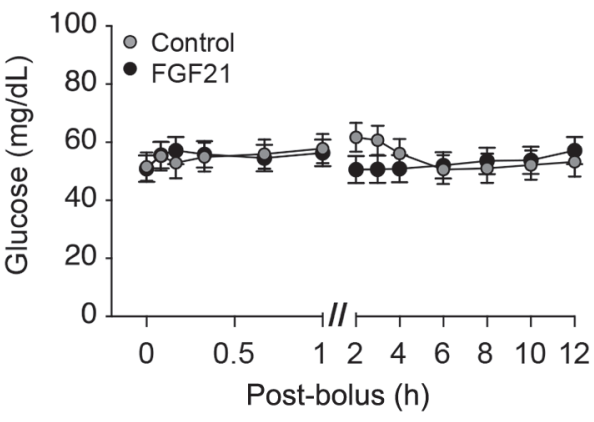

B Adipose tissue

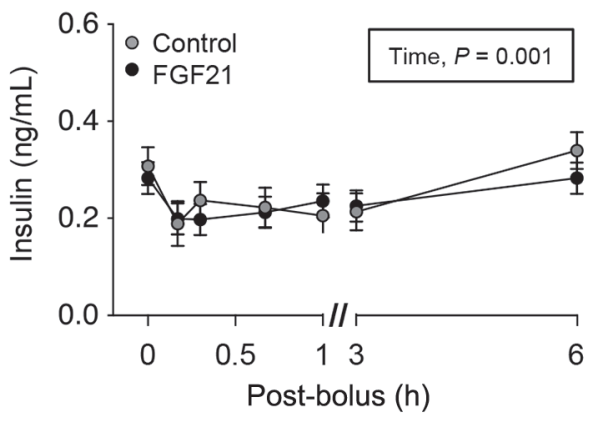

C Plasma
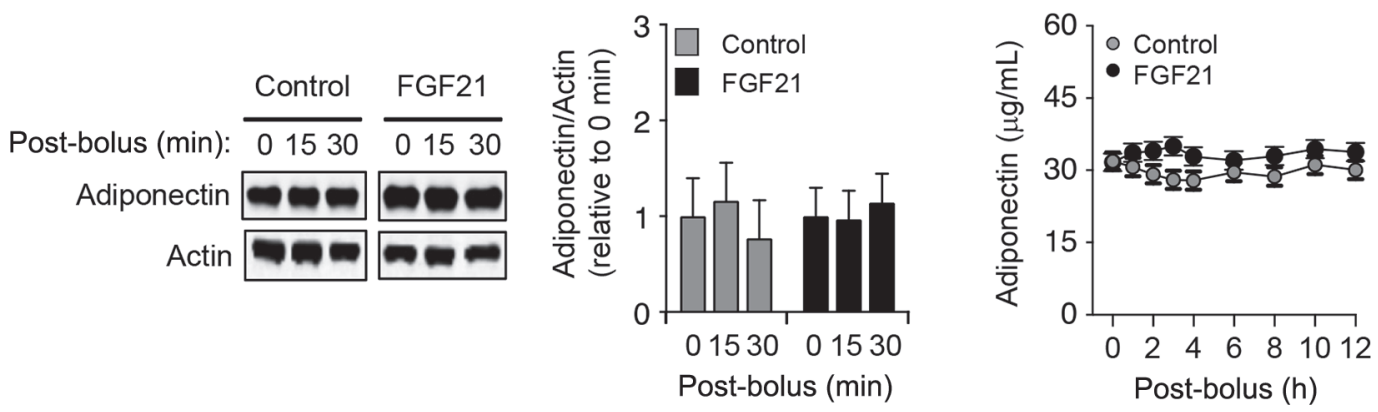

Figure 3. Effect of acute administration of fibroblast growth factor-21 (FGF21) on plasma glucose, insulin, and adiponectin. Dairy cows received an i.v. bolus of excipient (control) or human FGF21 (3 mg/kg of BW) on d $12.6 \pm 2.2$ of lactation. (A) Blood samples were collected over the 12-h period following the i.v. bolus, and plasma was analyzed for plasma glucose and insulin concentrations. Each point represents the $\mathrm{LSM} \pm \mathrm{SE}$ of plasma glucose or insulin $(\mathrm{n}=6-7 \mathrm{cows})$. (B) Left: Biopsies of adipose tissue were obtained immediately before the i.v. bolus at time 0 and then 15 and 30 min later. Total cellular extracts were prepared and analyzed by Western immunoblotting. Adiponectin and $\beta$-actin (Actin) signals shown are from a representative control and FGF21-treated cow. Right: the adiponectin/ $\beta$-actin signal was calculated and expressed relative to time 0, with each bar representing the LSM $\pm \mathrm{SE}$ of 6 to 7 cows per treatment. (C) Blood samples were collected over the 12 -h period following the i.v. bolus, and plasma was analyzed for adiponectin concentration. Each point represents the LSM \pm SE of plasma adiponectin ( $\mathrm{n}=6-7$ cows).

secreting INS-1E $\beta$-cells (Wente et al., 2006; Moyers et al., 2007), but to our knowledge, have not been reported in adipose tissue of any species. Overall, these data show that the human FGF21 variant LY2405319 is biologically active in cattle and identify WAT as a direct FGF21 target.

Direct FGF21 effects in liver remain controversial because ERK1/2 activation has been observed in primary hepatocytes and mouse liver in some experiments $(\mathrm{Xu}$ et al., 2009b; Fisher et al., 2011) but not in others (Kurosu et al., 2007). In the context of early lactation, we were unable to detect any evidence of hepatic FGF21 signaling, including ERK1/2 activation. This lack of signaling likely relates to negligible expression of FGFR $1 c$ as there is growing evidence that it is not only the preferred but also the physiologically relevant FGF21 signaling FGFR isoform. First, formation of competent FGF21 signaling complexes requires physical interactions between the co-receptor $\beta$-Klotho and the FGFR moiety (Ogawa et al., 2007). Such interactions have been demonstrated with FGFR1c but are negligible or absent with FGFR2c or FGFR3c. Strong $\beta$-Klotho interactions were also seen with FGFR4, but this receptor is unable to convey FGF21 signaling ( $\mathrm{Ku}$ rosu et al., 2007). Second, studies in 3T3-L1 fibroblasts demonstrate that FGF21 responsiveness depends on adequate expression of both FGFR1c and $\beta$-Klotho (Kharitonenkov et al., 2008). Moreover, FGF21 no longer triggers signaling responses, including ERK1/2 activation, after genetic ablation of FGFR1 in mice (Foltz et al., 2012).

The FGF21 has the remarkable effects of correcting the hyperglycemia and hyperinsulinemia seen in mice and rhesus monkeys suffering from type 2 diabetes or obesity or both. These effects are seen within $1 \mathrm{~h}$ of a single FGF21 dose and are sustained during chronic administration (Kharitonenkov et al., 2007; Xu et al., 2009b). These beneficial effects are associated with im- 
A Plasma
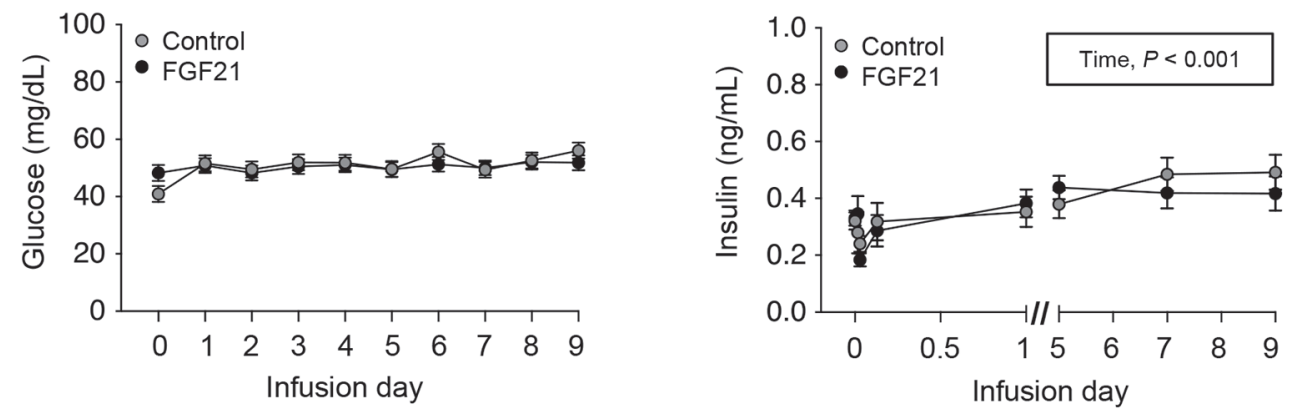

B Glucose tolerance test
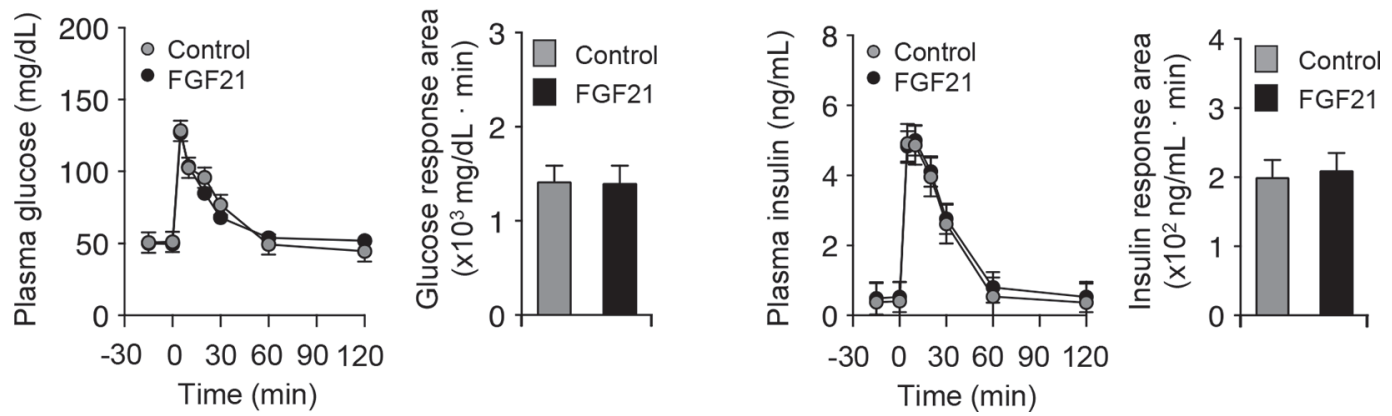

Figure 4. Effect of chronic administration of fibroblast growth factor-21 (FGF21) on plasma glucose and insulin. Dairy cows received a constant i.v. infusion of excipient (control) or human FGF21 $(6.3 \mathrm{mg} / \mathrm{kg}$ of metabolic BW per day) starting on d $14.6 \pm 2.2$ of lactation and lasting for 9 consecutive days. (A) Blood samples were collected daily during the constant i.v. infusion, and plasma was analyzed for glucose and insulin concentrations. Each point represents the LSM \pm SE of plasma glucose or insulin $(\mathrm{n}=6-7$ cows). The significant effect of Time is reported for insulin. (B) A glucose tolerance test was performed on d 8 of treatment. Blood samples were collected during the glucose tolerance test, and plasma was analyzed for glucose and insulin concentrations. Plasma concentrations and response areas are shown on the left for glucose and on the right for insulin. Each bar for the glucose and insulin response areas represents the LSM \pm SE of 6 to 7 cows per treatment.

proved glucose disposal during GTT despite an attenuated insulin response and with increased rates of glucose infusion during hyperinsulinemic-euglycemic clamps (Xu et al., 2009a,b). In contrast, we saw no comparable FGF21 effects on plasma glucose and insulin after bolus or chronic FGF21 treatment and no effect on GTT variables after chronic treatment. Lack of such effects is unlikely to reflect insufficient FGF21 exposure as we used doses well above minimal doses capable of producing these effects in other species (Kharitonenkov et al., 2007; Xu et al., 2009b). It may relate to FGF21 acting predominantly as an insulin sensitizer rather than a direct stimulator of glucose uptake. Indeed, FGF21 has never been shown to produce hypoglycemia on its own even at extremely high dosage and has little to no effect on plasma glucose and insulin in normal animals (Kharitonenkov et al., 2005, 2007). Given these observations, it is not surprising that the effects of FGF21 on plasma glucose and insulin in early-lactating dairy cows were not observed as the concentration of both variables is at the low end of the normal range.
Therapy with FGF21 has consistently increased the plasma concentration of the adipose tissue-derived hormone adiponectin in rodents and nonhuman primates (Kharitonenkov et al., 2007; Holland et al., 2013; Lin et al., 2013). This effect occurs within 15 min of exposure in 3T3-L1 adipocytes and primary mouse adipocytes as well as in vivo, reflecting a sudden burst of adiponectin secretion (Holland et al., 2013; Lin et al., 2013). Increased plasma adiponectin is also sustained during chronic FGF21 treatment through increased adipose tissue expression of adiponectin and the endoplasmic reticulum chaperones DSBA-L and Ero1A (Lin et al., 2013). These chaperones are necessary for the assembly of adiponectin monomers into higher molecular weight oligomers and for their secretion (Qiang et al., 2007; Liu et al., 2008). Adiponectin has been suggested to be a mediator of insulin-sensitizing FGF21 effects on tissues with little or no meaningful FGF21 response capability, such as liver and skeletal muscle (Lin et al., 2013). Moreover, adiponectin is produced by adipose tissue, the major peripheral FGF21 target tissue, and 
A Adipose tissue

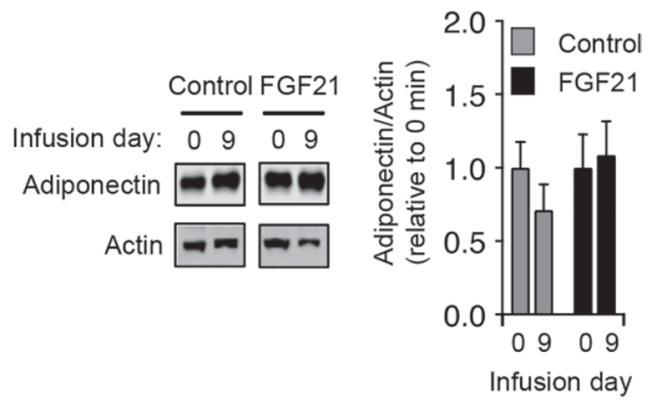

\section{B Plasma}

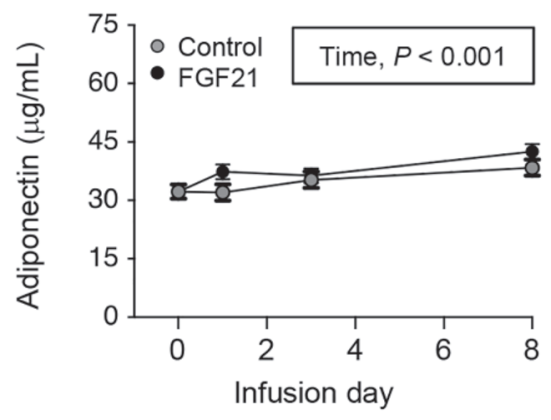

\section{Adiponectin production}

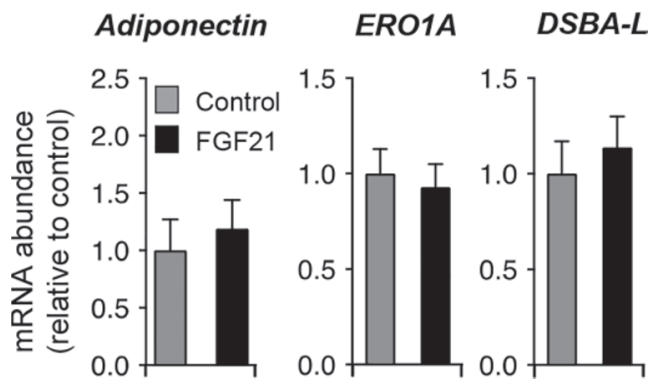

Figure 5. Effect of a chronic increase in plasma fibroblast growth factor-21 (FGF21) on indices of adiponectin production. Dairy cows received a constant i.v. infusion of excipient (control) or human FGF21 $(6.3 \mathrm{mg} / \mathrm{kg}$ of metabolic BW per day) starting on d $14.6 \pm 2.2$ of lactation and lasting for 9 consecutive days. (A) Biopsies of adipose tissue were obtained immediately before the i.v. bolus $(\mathrm{d} 0)$ and at the end of infusion (d 9). Total cellular extracts were prepared and analyzed by Western immunoblotting. Left: adiponectin and $\beta$-actin (Actin) signals shown are from a representative excipient and FGF21-treated cow. Right: the adiponectin/ $\beta$-actin signal was calculated and expressed relative to $\mathrm{d} 0$, with each bar representing the LSM $\pm \mathrm{SE}$ of 6 to 7 cows per treatment. (B) Blood samples were collected during the constant i.v. infusion, and plasma was analyzed for adiponectin concentration. Each point represents the LSM \pm SE of plasma adiponectin $(\mathrm{n}=$ 6-7 cows). The significant effect of Time is reported. (C) Total RNA was isolated from adipose tissue obtained at the end of the 9-d infusion and analyzed for mRNA abundance of adiponectin, ERO1-like protein $\alpha(E R O 1 A)$, and disulfide-bond A oxidoreductase-like protein $(D S B A-L)$. Expression of each gene is relative to the control group. Each bar represents the $\mathrm{LSM} \pm \mathrm{SE}$ of $\mathrm{mRNA}$ abundance for the indicated gene $(\mathrm{n}=6-7$ cows $)$. is itself an insulin-sensitizing hormone (Kadowaki et al., 2008; Liu and Liu, 2009; Shetty et al., 2009). In support of this model, the ability of acute and chronic FGF21 therapy to improve insulin sensitivity in obese mice is lost in adiponectin knockout mice despite robust ERK1/2 activation in adipose tissue (Lin et al., 2013). Dairy cows have reduced plasma adiponectin in early lactation, so the possibility that FGF21 therapy could reverse this condition was attractive. We examined this possibility by 3 independent approaches. First, we used Western immunoblot analysis to determine whether adipose tissue is depleted of adiponectin immediately after the FGF21 bolus. Second, we analyzed the profile of plasma adiponectin following both acute and chronic FGF21 treatment. Finally, we asked whether FGF21 stimulated adipose tissue mRNA abundance of adiponectin and associated molecular chaperones. However, none of these approaches provided evidence for FGF21 stimulation of adiponectin in early-lactating dairy cows.

In summary, we show that energy-deficient, earlylactating dairy cows mount robust FGF21 signaling responses in WAT but not in liver, owing to low expression of the preferred FGF21 receptor, FGFR1c. Acute and chronic FGF21 treatment, however, did not trigger previously reported effects on variables associated with insulin action (i.e., reduction in plasma glucose and insulin and increase in plasma adiponectin). These previous studies were almost exclusively performed in animals experiencing excessive nutrition and obesity, suggesting nutrition status is a major determinant of FGF21 actions. Future studies are needed to assess the possibility that the lack of FGF21 effects in earlylactating dairy cows relate to their intense nutritional deficit.

\section{ACKNOWLEDGMENTS}

This material is based upon work that is supported by the National Institute of Food and Agriculture, U.S. Department of Agriculture, under award number 2010-65206-20683 and Hatch/Multistate projects under 1000962 and 1017053 . J. W. Perfield II is a paid employee of Eli Lilly and Company and may own company stock or possess stock options. We thank Alexei Kharitonenkov (Novo Nordisk Research Center Indianapolis, Indianapolis, IN) for his interest in and support of this project. We also thank Phillip Gondim (Cornell University, Ithaca, NY) for help in performing the animal work.

\section{REFERENCES}

Adams, A. C., C. A. Halstead, B. C. Hansen, A. R. Irizarry, J. A. Martin, S. R. Myers, V. L. Reynolds, H. W. Smith, V. J. Wroblewski, 
and A. Kharitonenkov. 2013. LY2405319, an engineered FGF21 variant, improves the metabolic status of diabetic monkeys. PLoS One 8:e65763. https://doi.org/10.1371/journal.pone.0065763.

Bell, A. W. 1995. Regulation of organic nutrient metabolism during transition from late pregnancy to early lactation. J. Anim. Sci. $73: 2804-2819$

Bell, A. W., and D. E. Bauman. 1997. Adaptations of glucose metabolism during pregnancy and lactation. J. Mammary Gland Biol. Neoplasia 2:265-278.

Block, S. S., W. R. Butler, R. A. Ehrhardt, A. W. Bell, M. E. Van Amburgh, and Y. R. Boisclair. 2001. Decreased concentration of plasma leptin in periparturient dairy cows is caused by negative energy balance. J. Endocrinol. 171:339-348.

Boisclair, Y. R., S. R. Wesolowski, J. W. Kim, and R. A. Ehrhardt. 2006. Role of growth hormone and leptin in the periparturient dairy cow. K. Sejrsen, T. Hveplund, and M. O. Nielsen, ed. Wageningen Academic Publishers, Wageningen, the Netherlands.

Caixeta, L. S., S. L. Giesy, C. S. Krumm, J. W. Perfield, A. Butterfield, and Y. R. Boisclair. 2019. Fibroblast growth factor-21 (FGF21) administration to early-lactating dairy cows. II. Pharmacokinetics, whole-animal performance, and lipid metabolism. J. Dairy Sci. https://doi.org/10.3168/jds.2019-16695.

Caixeta, L. S., S. L. Giesy, C. S. Krumm, J. W. Perfield, A. Butterfield, K. M. Schoenberg, D. C. Beitz, and Y. R. Boisclair. 2017. Effect of circulating glucagon and free fatty acids on hepatic FGF21 production in dairy cows. Am. J. Physiol. Regul. Integr. Comp. Physiol. 313:R526-R534. https://doi.org/10.1152/ajpregu.00197 .2017 .

De Koster, J. D., and G. Opsomer. 2013. Insulin resistance in dairy cows. Vet. Clin. North Am. Food Anim. Pract. 29:299-322. https: //doi.org/10.1016/j.cvfa.2013.04.002.

Drackley, J. K., T. R. Overton, and G. N. Douglas. 2001. Adaptations of glucose and long-chain fatty acid metabolism in liver of dairy cows during the periparturient period. J. Dairy Sci. 84:E100-E112. https://doi.org/10.3168/jds.S0022-0302(01)70204-4.

Ehrhardt, R. A., R. M. Slepetis, A. W. Bell, and Y. R. Boisclair. 2001. Maternal leptin is elevated during pregnancy in sheep. Domest. Anim. Endocrinol. 21:85-96.

Fisher, F. M., J. L. Estall, A. C. Adams, P. J. Antonellis, H. A. Bina, J. S. Flier, A. Kharitonenkov, B. M. Spiegelman, and E. MaratosFlier. 2011. Integrated regulation of hepatic metabolism by fibroblast growth factor 21 (FGF21) in vivo. Endocrinology 152:29963004. https://doi.org/10.1210/en.2011-0281.

Fisher, F. M., and E. Maratos-Flier. 2016. Understanding the physiology of FGF21. Annu. Rev. Physiol. 78:223-241. https://doi.org/10 .1146/annurev-physiol-021115-105339.

Foltz, I. N., S. Hu, C. King, X. Wu, C. Yang, W. Wang, J. Weiszmann, J. Stevens, J. S. Chen, N. Nuanmanee, J. Gupte, R. Komorowski, L. Sekirov, T. Hager, T. Arora, H. Ge, H. Baribault, F. Wang, J. Sheng, M. Karow, M. Wang, Y. Luo, W. McKeehan, Z. Wang, M. M. Véniant, and Y. Li. 2012. Treating diabetes and obesity with an FGF21-mimetic antibody activating the $\beta$ Klotho/FGFR1c receptor complex. Sci. Transl. Med. 4:162ra153. https://doi.org/10 .1126 /scitranslmed.3004690.

Fon Tacer, K., A. L. Bookout, X. Ding, H. Kurosu, G. B. John, L. Wang, R. Goetz, M. Mohammadi, M. Kuro-o, D. J. Mangelsdorf, and S. A. Kliewer. 2010. Research resource: Comprehensive expression atlas of the fibroblast growth factor system in adult mouse. Mol. Endocrinol. 24:2050-2064. https://doi.org/10.1210/ me.2010-0142.

Gaich, G., J. Y. Chien, H. Fu, L. C. Glass, M. A. Deeg, W. L. Holland, A. Kharitonenkov, T. Bumol, H. K. Schilske, and D. E. Moller. 2013. The effects of LY2405319, an FGF21 analog, in obese human subjects with type 2 diabetes. Cell Metab. 18:333-340.

Giesy, S. L., B. Yoon, W. B. Currie, J. W. Kim, and Y. R. Boisclair. 2012. Adiponectin deficit during the precarious glucose economy of early lactation in dairy cows. Endocrinology 153:5834-5844. https: //doi.org/10.1210/en.2012-1765.

Holland, W. L., A. C. Adams, J. T. Brozinick, H. H. Bui, Y. Miyauchi, C. M. Kusminski, S. M. Bauer, M. Wade, E. Singhal, C. C. Cheng, K. Volk, M.-S. Kuo, R. Gordillo, A. Kharitonenkov, and P. E.
Scherer. 2013. An FGF21-adiponectin-ceramide axis controls energy expenditure and insulin action in mice. Cell Metab. 17:790-797. https://doi.org/10.1016/j.cmet.2013.03.019.

Kadowaki, T., T. Yamauchi, and N. Kubota. 2008. The physiological and pathophysiological role of adiponectin and adiponectin receptors in the peripheral tissues and CNS. FEBS Lett. 582:74-80. https://doi.org/10.1016/j.febslet.2007.11.070.

Kharitonenkov, A., J. M. Beals, R. Micanovic, B. A. Strifler, R. Rathnachalam, V. J. Wroblewski, S. Li, A. Koester, A. M. Ford, T. Coskun, J. D. Dunbar, C. C. Cheng, C. C. Frye, T. F. Bumol, and D. E. Moller. 2013. Rational design of a fibroblast growth factor 21-based clinical candidate, LY2405319. PLoS One 8:e58575. https://doi.org/10.1371/journal.pone.0058575.

Kharitonenkov, A., J. D. Dunbar, H. A. Bina, S. Bright, J. S. Moyers, C. Zhang, L. Ding, R. Micanovic, S. F. Mehrbod, M. D. Knierman, J. E. Hale, T. Coskun, and A. B. Shanafelt. 2008. FGF-21/FGF-21 receptor interaction and activation is determined by betaKlotho. J. Cell. Physiol. 215:1-7. https://doi.org/10.1002/jcp.21357.

Kharitonenkov, A., T. L. Shiyanova, A. Koester, A. M. Ford, R. Micanovic, E. J. Galbreath, G. E. Sandusky, L. J. Hammond, J. S. Moyers, R. A. Owens, J. Gromada, J. T. Brozinick, E. D. Hawkins, V. J. Wroblewski, D.-S. Li, F. Mehrbod, S. R. Jaskunas, and A. B. Shanafelt. 2005. FGF-21 as a novel metabolic regulator. J. Clin. Invest. 115:1627-1635. https://doi.org/10.1172/JCI23606.

Kharitonenkov, A., V. J. Wroblewski, A. Koester, Y.-F. Chen, C. K. Clutinger, X. T. Tigno, B. C. Hansen, A. B. Shanafelt, and G. J. Etgen. 2007. The metabolic state of diabetic monkeys is regulated by fibroblast growth factor-21. Endocrinology 148:774-781. https: //doi.org/10.1210/en.2006-1168.

Krumm, C. S., S. L. Giesy, L. S. Caixeta, W. R. Butler, H. Sauerwein, J. W. Kim, and Y. R. Boisclair. 2017. Effect of hormonal and energy-related factors on plasma adiponectin in transition dairy cows. J. Dairy Sci. https://doi.org/10.3168/jds.2017-13274.

Krumm, C. S., S. L. Giesy, C. L. Orndorff, and Y. R. Boisclair. 2018. Variation in $\mathrm{x}$-box binding protein 1 (XBP1) expression and its dependent endoplasmic reticulum chaperones does not regulate adiponectin secretion in dairy cows. J. Dairy Sci. 101:5559-5570. https://doi.org/10.3168/jds.2017-14048.

Kurosu, H., M. Choi, Y. Ogawa, A. S. Dickson, R. Goetz, A. V. Eliseenkova, M. Mohammadi, K. P. Rosenblatt, S. A. Kliewer, and M. Kuro-o. 2007. Tissue-specific expression of betaKlotho and fibroblast growth factor (FGF) receptor isoforms determines metabolic activity of FGF19 and FGF21. J. Biol. Chem. 282:26687-26695. https://doi.org/10.1074/jbc.M704165200.

Lin, Z., H. Tian, K. S. L. Lam, S. Lin, R. C. L. Hoo, M. Konishi, N. Itoh, Y. Wang, S. R. Bornstein, A. Xu, and X. Li. 2013. Adiponectin mediates the metabolic effects of FGF21 on glucose homeostasis and insulin sensitivity in mice. Cell Metab. 17:779-789. https:/ /doi.org/10.1016/j.cmet.2013.04.005.

Liu, M., and F. Liu. 2009. Transcriptional and post-translational regulation of adiponectin. Biochem. J. 425:41-52. https://doi.org/10 .1042/BJ20091045.

Liu, M., L. Zhou, A. Xu, K. S. L. Lam, M. D. Wetzel, R. Xiang, J. Zhang, X. Xin, L. Q. Dong, and F. Liu. 2008. A disulfide-bond A oxidoreductase-like protein (DsbA-L) regulates adiponectin multimerization. Proc. Natl. Acad. Sci. USA 105:18302-18307. https:// doi.org/10.1073/pnas.0806341105.

Markan, K. R., and M. J. Potthoff. 2016. Metabolic fibroblast growth factors (FGFs): Mediators of energy homeostasis. Semin. Cell Dev. Biol. 53:85-93. https://doi.org/10.1016/j.semcdb.2015.09.021.

Mielenz, M., B. Mielenz, S. P. Singh, C. Kopp, J. Heinz, S. Häussler, and H. Sauerwein. 2013. Development, validation, and pilot application of a semiquantitative Western blot analysis and an ELISA for bovine adiponectin. Domest. Anim. Endocrinol. 44:121-130. https://doi.org/10.1016/j.domaniend.2012.10.004.

Moyers, J. S., T. L. Shiyanova, F. Mehrbod, J. D. Dunbar, T. W. Noblitt, K. A. Otto, A. Reifel-Miller, and A. Kharitonenkov. 2007. Molecular determinants of FGF-21 activity-synergy and cross-talk with PPARgamma signaling. J. Cell. Physiol. 210:1-6. https://doi .org/10.1002/jcp.20847. 
Ogawa, Y., H. Kurosu, M. Yamamoto, A. Nandi, K. P. Rosenblatt, R. Goetz, A. V. Eliseenkova, M. Mohammadi, and M. Kuro-o. 2007. BetaKlotho is required for metabolic activity of fibroblast growth factor 21. Proc. Natl. Acad. Sci. USA 104:7432-7437. https://doi .org/10.1073/pnas.0701600104.

Qiang, L., H. Wang, and S. R. Farmer. 2007. Adiponectin secretion is regulated by SIRT1 and the endoplasmic reticulum oxidoreductase Ero1-L alpha. Mol. Cell. Biol. 27:4698-4707. https://doi.org/10 .1128/MCB.02279-06.

Schoenberg, K. M., S. L. Giesy, K. J. Harvatine, M. R. Waldron, C. Cheng, A. Kharitonenkov, and Y. R. Boisclair. 2011. Plasma FGF21 is elevated by the intense lipid mobilization of lactation. Endocrinology 152:4652-4661. https://doi.org/10.1210/en.2011 -1425 .

Sechen, S. J., S. N. McCutcheon, and D. E. Bauman. 1989. Response to metabolic challenges in early lactation dairy cows during treatment with bovine somatotropin. Domest. Anim. Endocrinol. $6: 141-154$.

Shetty, S., C. M. Kusminski, and P. E. Scherer. 2009. Adiponectin in health and disease: Evaluation of adiponectin-targeted drug development strategies. Trends Pharmacol. Sci. 30:234-239. https://doi .org/10.1016/j.tips.2009.02.004.

Stern, J. H., J. M. Rutkowski, and P. E. Scherer. 2016. Adiponectin, leptin, and fatty acids in the maintenance of metabolic homeostasis through adipose tissue crosstalk. Cell Metab. 23:770-784. https: //doi.org/10.1016/j.cmet.2016.04.011.

Thorn, S. R., S. Purup, W. S. Cohick, M. Vestergaard, K. Sejrsen, and Y. R. Boisclair. 2006. Leptin does not act directly on mammary epithelial cells in prepubertal dairy heifers. J. Dairy Sci. 89:1467-1477.

Véniant, M. M., C. Hale, J. Helmering, M. M. Chen, S. Stanislaus, J. Busby, S. Vonderfecht, J. Xu, and D. J. Lloyd. 2012. FGF21 promotes metabolic homeostasis via white adipose and leptin in mice. PLoS One 7:e40164. https://doi.org/10.1371/journal.pone .0040164 .

Wente, W., A. M. Efanov, M. Brenner, A. Kharitonenkov, A. Köster, G. E. Sandusky, S. Sewing, I. Treinies, H. Zitzer, and J. Gromada. 2006. Fibroblast growth factor-21 improves pancreatic beta-cell function and survival by activation of extracellular signal-regulated kinase 1/2 and Akt signaling pathways. Diabetes 55:2470-2478. https://doi.org/10.2337/db05-1435.

Xu, J., D. J. Lloyd, C. Hale, S. Stanislaus, M. Chen, G. Sivits, S. Vonderfecht, R. Hecht, Y.-S. Li, R. A. Lindberg, J.-L. Chen, D. Y. Jung, Z. Zhang, H.-J. Ko, J. K. Kim, and M. M. Véniant. 2009a. Fibroblast growth factor 21 reverses hepatic steatosis, increases energy expenditure, and improves insulin sensitivity in diet-induced obese mice. Diabetes 58:250-259. https://doi.org/10 $.2337 / \mathrm{db08-0392.}$

Xu, J., S. Stanislaus, N. Chinookoswong, Y. Y. Lau, T. Hager, J. Patel, H. Ge, J. Weiszmann, S.-C. Lu, M. Graham, J. Busby, R. Hecht, Y.-S. Li, Y. Li, R. Lindberg, and M. M. Véniant. 2009b. Acute glucose-lowering and insulin-sensitizing action of FGF21 in insulin-resistant mouse models-association with liver and adipose tissue effects. Am. J. Physiol. Endocrinol. Metab. 297:E1105E1114. https://doi.org/10.1152/ajpendo.00348.2009.

\section{ORCIDS}

L. S. Caixeta @ https://orcid.org/0000-0001-9577-4989

H. Sauerwein () https://orcid.org/0000-0002-6905-4053

Y. R. Boisclair () https://orcid.org/0000-0002-6621-498X 